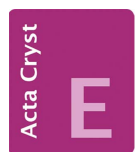

CRYSTALLOGRAPHIC COMMUNICATIONS

ISSN 2056-9890

Received 24 February 2016

Accepted 26 February 2016

Edited by M. Zeller, Youngstown State University, USA

Keywords: crystal structure; isonicotinamide; hydrochloride; hydrogen bonding.

CCDC reference: 1455942

Supporting information: this article has supporting information at journals.iucr.org/e

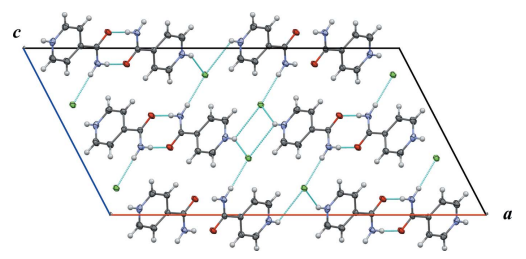

OPEN $\odot$ ACCESS

\section{Crystal structure of 4-carbamoylpyridinium chloride}

\author{
Simon M. Fellows and Timothy J. Prior* \\ Department of Chemistry, University of Hull, Cottingham Road, Hull HU6 7RX, United Kingdom. *Correspondence \\ e-mail: t.prior@hull.ac.uk
}

The hydrochloride salt of isonicotinamide, $\mathrm{C}_{6} \mathrm{H}_{7} \mathrm{~N}_{2} \mathrm{O}^{+} \cdot \mathrm{Cl}^{-}$, has been synthesized from a dilute solution of hydrochloric acid in acetonitrile. The compound displays monoclinic symmetry (space group $C 2 / c$ ) at $150 \mathrm{~K}$, similar to the related hydrochloride salt of nicotinamide. The asymmetric unit contains one protonated isonicotinamide molecule and a chloride anion. An array of hydrogen-bonding interactions, including a peculiar bifurcated pyridiniumchloride interaction, results in linear chains running almost perpendicularly in the $[150]$ and $[1 \overline{50}]$ directions within the structure. A description of the hydrogen-bonding network and comparison with similar compounds are presented.

\section{Chemical context}

Often compounds which exhibit a desirable biological function may not possess the correct physical properties for practical usage. The ability to manipulate the properties of a compound in a controlled manner, while maintaining the biological activity, is one of the ultimate goals of crystal engineering (Desiraju et al., 2011). Converting a biologically active compound into its hydrochloride salt has proven a successful technique in this regard (Byrn et al., 1999). The structural determination and analysis of neutral, co-crystalline, and salt forms of various molecules is necessary in order to expand the library of reliable tools that can be used in the design of new materials.

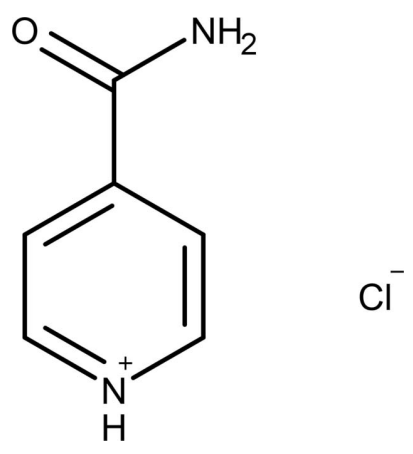

Isonicotinamide is a useful compound in crystal engineering as it possesses amide and pyridyl groups which have the capability to form a plethora of well established and predictable hydrogen-bonding arrangements (Bhogala et al., 2004). It also displays polymorphism in the solid state on account of its flexible hydrogen-bonding capacity (Aakeröy et al., 2003; Li et al., 2011). As a result, the molecule has been heavily investigated by many groups as a co-crystal former in lots of different 


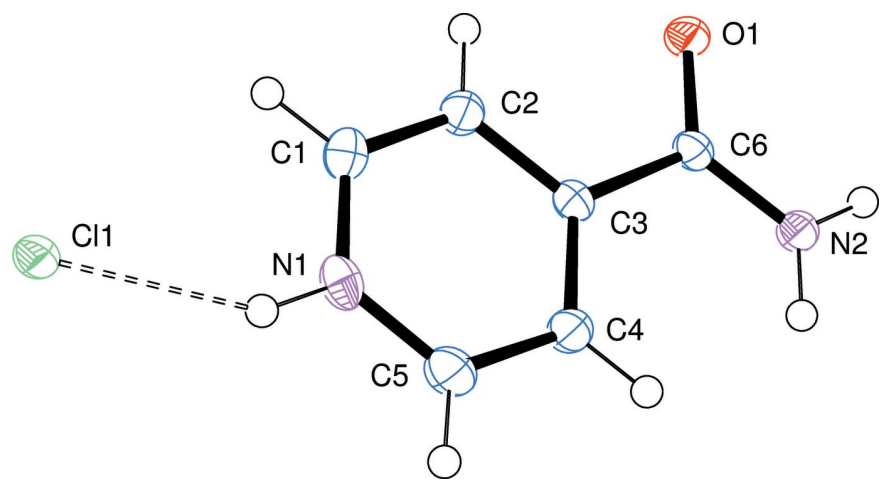

Figure 1

The asymmetric unit of the title compound, showing the atom-numbering scheme. Displacement ellipsoids are drawn at the $50 \%$ probability level. The dashed line represents a hydrogen bond.

scenarios (Vishweshwar et al., 2003; Bhogala et al., 2005; Aakeröy et al., 2007; Thompson et al., 2011; Tothadi \& Desiraju, 2012; Dubey \& Desiraju, 2014; Kerr et al., 2015). The compound is also of mild pharmaceutical interest given its similarity to nicotinamide, the amide of Vitamin $B_{3}$. The hydrochloride salt of this molecule has been synthesized and the structure determined, the results of which are discussed herein.

\section{Structural commentary}

The asymmetric unit of the title compound, shown in Fig. 1, consists of one chloride anion and a protonated isonicotinamide cation, confirmed by the identification of a proton $0.9 \AA$ from the pyridine $\mathrm{N}$ atom in a difference Fourier map. The isonicotinamide cation is planar: the root-mean-square deviation of the pyridinium ring is $0.0062 \AA$, with an angle of $1.3(2)^{\circ}$ between the planes of the pyridinium and amide
Table 1

Hydrogen-bond geometry $\left(\AA,^{\circ}\right)$.

\begin{tabular}{lllll}
\hline$D-\mathrm{H} \cdots A$ & $D-\mathrm{H}$ & $\mathrm{H} \cdots A$ & $D \cdots A$ & $D-\mathrm{H} \cdots A$ \\
\hline $\mathrm{C} 1-\mathrm{H} 1 \cdots \mathrm{O} 1^{\mathrm{i}}$ & 0.95 & 2.74 & $3.295(2)$ & 118 \\
$\mathrm{C} 2-\mathrm{H} 2 \cdots 1^{\mathrm{i}}{ }^{\mathrm{ii}}$ & 0.92 & 2.61 & $3.2205(18)$ & 124 \\
$\mathrm{C} 4-\mathrm{H} 4 \cdots \mathrm{Cl} 1^{1 i}$ & 0.95 & 2.59 & $3.5377(15)$ & 172 \\
$\mathrm{C} 5-\mathrm{H} 5 \cdots \mathrm{Cl} 1^{\mathrm{iii}}$ & 0.93 & 2.62 & $3.3284(15)$ & 133 \\
$\mathrm{~N} 1-\mathrm{H} 1 A \cdots \mathrm{Cl} 1$ & 0.89 & 2.24 & $3.0416(12)$ & 149 \\
$\mathrm{~N} 1-\mathrm{H} 1 A \cdots \mathrm{Cl} 1^{\mathrm{iii}}$ & 0.89 & 2.95 & $3.4882(13)$ & 121 \\
$\mathrm{~N} 2-\mathrm{H} 2 A \cdots 1^{\text {iv }}$ & $0.88(2)$ & $2.02(2)$ & $2.8892(15)$ & $174(2)$ \\
$\mathrm{N} 2-\mathrm{H} 2 B \cdots \mathrm{Cl} 1^{\text {ii }}$ & $0.87(2)$ & $2.33(2)$ & $3.1907(13)$ & $169(2)$ \\
\hline
\end{tabular}

Symmetry codes: (i) $-x+\frac{1}{2}, y+\frac{1}{2},-z+\frac{3}{2}$; (ii) $x,-y+1, z-\frac{1}{2}$; (iii) $-x,-y+2,-z+1$; (iv) $-x+\frac{1}{2},-y-\frac{1}{2},-z+1$.

moieties. Analysis of structures in the Cambridge Structural Database (CSD, Version 5.37, update November 2015; Groom \& Allen, 2014) containing the 4-carbamoylpyridinium cation show that the angle between the amide and pyridinium planes can take any value between 0 and $50^{\circ}$ with no distinct configurational preference.

\section{Supramolecular features}

The most interesting feature of the crystal structure is the intermolecular interaction between the pyridinium groups and chloride ions. Two pyridinium protons form bifurcated hydrogen bonds to two chloride ions, forming an $R_{2}^{2}(4)$ ring motif which is positioned on a centre of inversion, as shown in Fig. $2(A)$. The interaction is similar to those found in many tetrahalometallate $\left[M X_{4}\right]^{2-}$ compounds, though primarily when the $\left[\mathrm{MX}_{4}\right]^{2-}$ unit is planar (Adams et al., 2006). It is also encountered in some hydrochloride salts of molecules incorporating a pyridinium group (Nattinen \& Rissanen, 2003; Zhao et al., 2008). The two unique $\mathrm{N}-\mathrm{H}$. . Cl hydrogen bonds formed by each proton in this arrangement are usually of

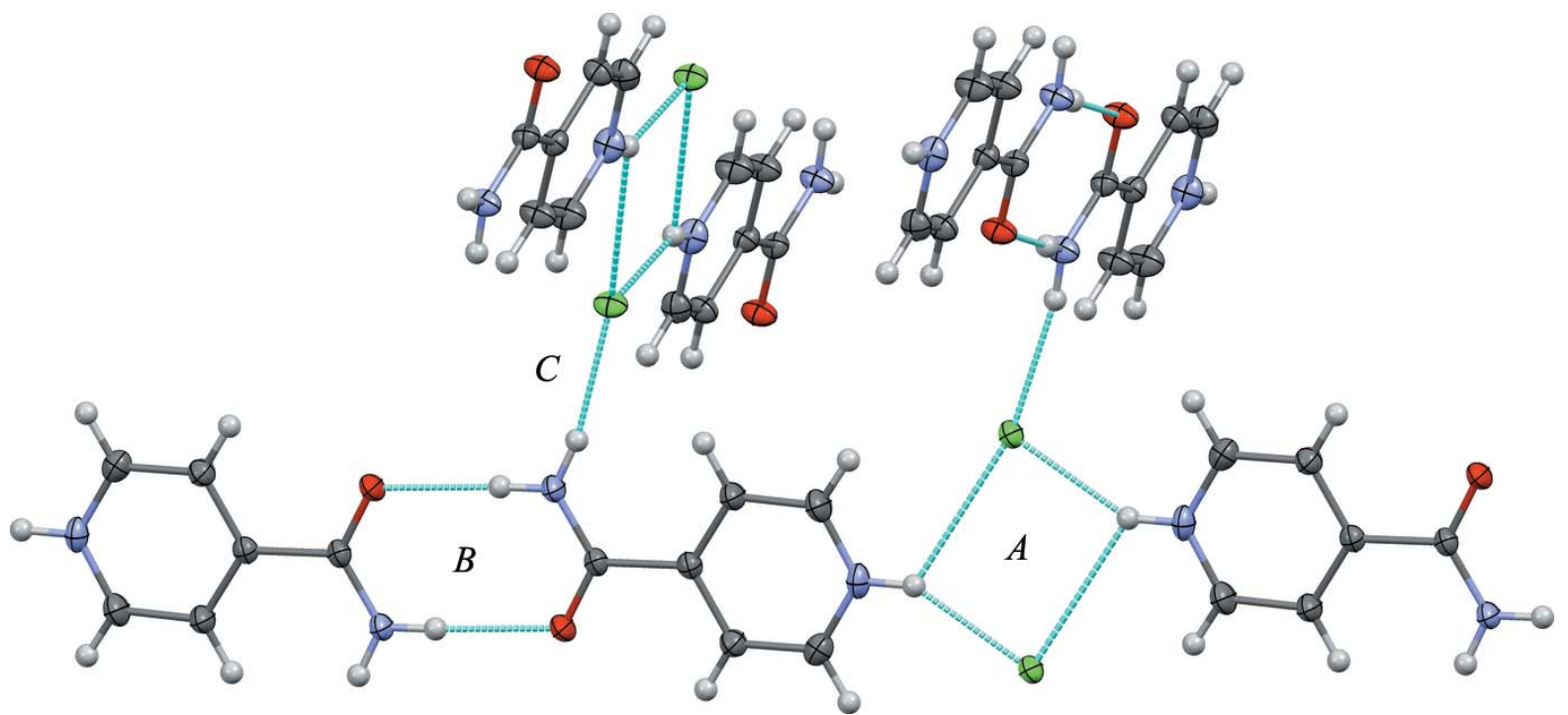

Figure 2

A view of the hydrogen bonding arrangements within 4-carbamoylpyridinium chloride, showing the pyridinium-chloride $(A)$ amide-amide $(B)$ and amine-chloride $(C)$ interactions. Hydrogen bonds are drawn as light-blue dashed lines. Possible $\mathrm{C}-\mathrm{H} \cdots X$ interactions have been omitted. 


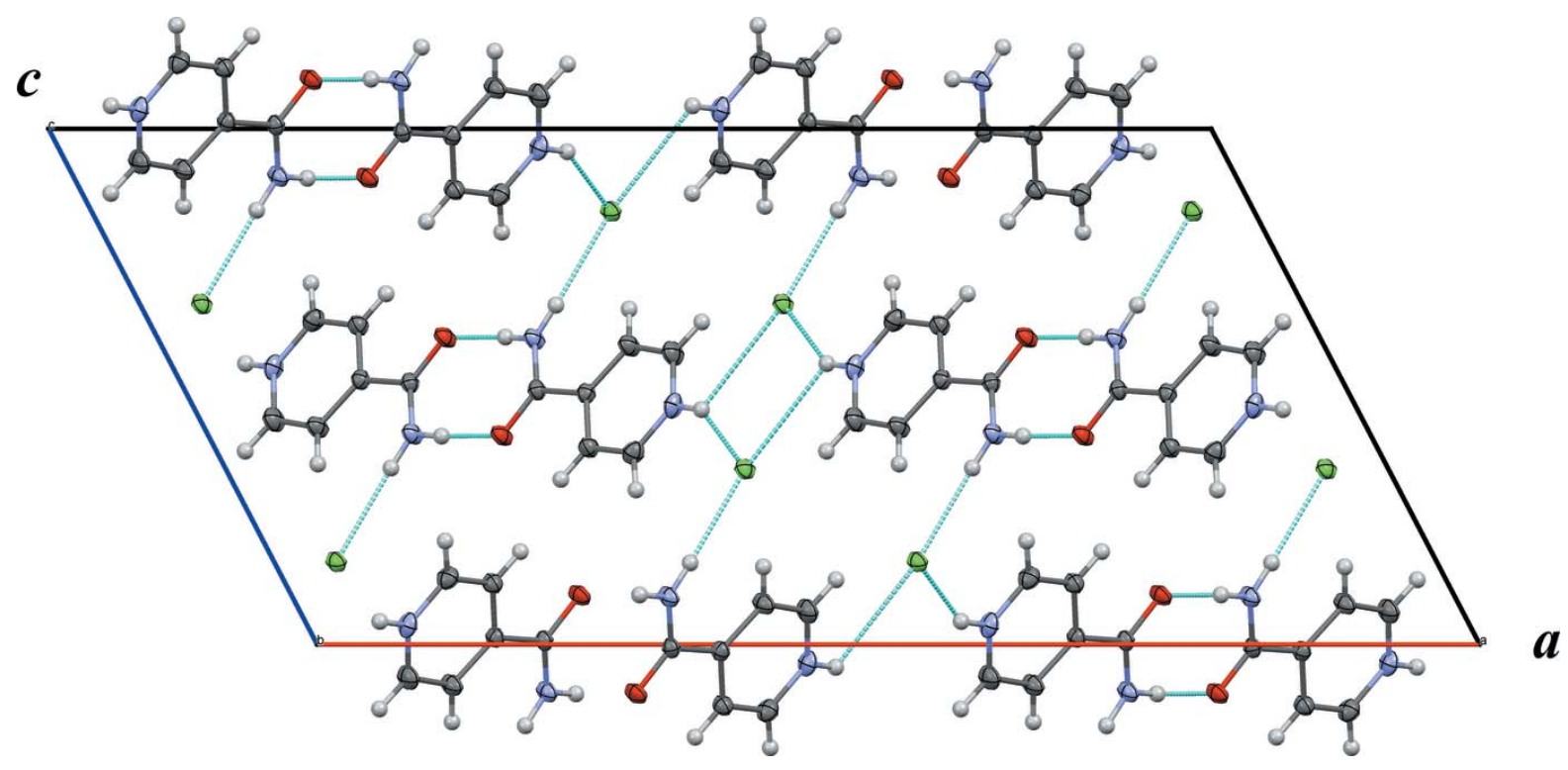

Figure 3

Crystal packing diagram of 4-carbamoylpyridinium chloride viewed along the $b$ axis. Hydrogen bonds are drawn as light-blue dashed lines.

similar length, though one is distinctly longer than the other in this compound $[\mathrm{N} \cdots \mathrm{Cl}=3.0416$ (12) $\AA$ and 3.4882 (13) $\AA$ ] The CSD (Version 5.37, update November 2015; Groom \& Allen, 2014) reveals 426 structures of the hydrochloride salts of molecules incorporating a pyridinium group. 21 of these display bifurcated pyridinium-chloride hydrogen bonds, of which only 16 possess the $R_{2}^{2}(4)$ ring motif. None of these simultaneously show the same asymmetry in the hydrogenbond lengths (ratio of two $\mathrm{N} \cdots \mathrm{Cl}$ lengths $=1.147$; ratio of $\mathrm{H} \cdot \mathrm{Cl}$ lengths $=1.317$ ), and planarity (r.m.s.d. $=0.0151 \AA$ ) of the interaction as the title compound. Given the lack of examples of bifurcated hydrogen bonds in this type of material, it seems likely that it is a result of maximizing the other possible intermolecular interactions for a given system, where the bifurcation is a compromise. In other words, one short, linear $\mathrm{N}-\mathrm{H} \cdots \mathrm{Cl}$ bond is ideal, though bifurcation is energetically more favourable than a single, weaker interaction.

The amine group of the amide moiety is directed toward the carboxyl group of an adjacent molecule related by a centre of inversion; this shows the existence of a classic $R_{2}^{2}(8)$ amideamide interaction, seen in Fig. $2(B)$. The combination of the two ring interactions form $C_{3}^{2}(16)$ chains running in the [150] and $[1 \overline{5} 0]$ directions, and are related by a $2_{1}$ screw axis. The two chain directions are almost perpendicular to each other $\left(82^{\circ}\right)$ and are held in this respective orientation by a $C_{4}^{3}(10)$ interaction which incorporates the $R_{2}^{2}(8)$ and $R_{2}^{2}(4)$ motifs, and hydrogen bonds between the protons not involved in the amide-amide interactions and the chloride ions of neighbouring chains, as shown in Fig. $2(C)$. For the overall packing arrangement, see Fig. 3. There is some evidence of $\mathrm{C}-\mathrm{H} \cdots X$ hydrogen bonds (Table 1); however, these only seem to reinforce the stronger interactions discussed above and their role in determining the crystal packing in this compound is unclear.

The related salt of nicotinamide contains the same amideamide interactions as in the title compound, though neither
3- or 4-carboxypyridinium chloride show the equivalent dicarboxylic acid interaction. (Gubin et al., 1989; Slouf, 2001; Adams et al., 2006). The chloride ions in these structures act only as hydrogen-bond acceptor atoms between donor atoms of molecules in the same chain, with no further interactions between the chains. It would be interesting to see how these almost classic co-crystal formers would behave when crystallized with the hydrochloride salts of other molecules, and whether the same hydrogen-bonding arrangements persist.

\section{Related structures}

For the crystal structure of 4-carbamoylpyridinium dihydrogen phosphate, see Gholivand et al. (2007); for 4-carbamoylpyridinium perchlorate, see Chen (2009); for nicotinamide hydrochloride, see Gubin et al. (1989); for nicotinic acid hydrochloride, see Slouf (2001); and for isonicotinic acid hydrochloride and a comprehensive study on the tetrachloroplatinate and palladate salts of similar pyridinium compounds, see Adams et al. (2006).

\section{Synthesis and crystallization}

Hydrochloric acid $(0.08 \mathrm{ml}, 12 \mathrm{M})$ in acetonitrile $(3 \mathrm{ml})$ was added to isonicotinamide $(0.244 \mathrm{~g}, 2 \mathrm{mmol})$ dissolved in acetonitrile $(25 \mathrm{ml})$. The resultant white mixture was heated until the precipitate dissolved and the solution left to evaporate slowly over several days, resulting in the formation of large colourless block-shaped crystals of the title compound.

\section{Refinement}

Crystal data, data collection and structure refinement details are summarized in Table 2. Hydrogen atoms were readily identified in difference Fourier maps. The pyridinium 
hydrogen atom was positioned in a geometrically optimized position; $\mathrm{N} 1-\mathrm{H} 1 A$ was constrained to a value of $0.88 \AA$ with an su of $0.03 \AA$. C-bound $\mathrm{H}$ atoms were sited with a riding model and the $\mathrm{C}-\mathrm{H}$ distance refined subject to the restraint that all $\mathrm{C}-\mathrm{H}$ distances should be the same with an su of $0.03 \AA$. The amide hydrogen atoms were refined freely subject to restraint that the two $\mathrm{N}-\mathrm{H}$ bond lengths were equal with an su of $0.03 \AA$ and the $\mathrm{H} \cdots \mathrm{H}$ distance was $\sqrt{ } 3 \times 1_{\mathrm{N}-\mathrm{H}}$ (su $0.03 \AA$ ) to set the $\mathrm{H}-\mathrm{N}-\mathrm{H}$ angle to $120^{\circ}$.

\section{References}

Aakeröy, C. B., Beatty, A. M., Helfrich, B. A. \& Nieuwenhuyzen, M. (2003). Cryst. Growth Des. 3, 159-165.

Aakeröy, C. B., Desper, J., Helfrich, B. A., Metrangolo, P., Pilati, T., Resnati, G. \& Stevenazzi, A. (2007). Chem. Commun. pp. 42364238.

Adams, C. J., Angeloni, A., Orpen, A. G., Podesta, T. J. \& Shore, B. (2006). Cryst. Growth Des. 6, 411-422.

Bhogala, B. R., Basavoju, S. \& Nangia, A. (2005). CrystEngComm, 7, 551-562.

Bhogala, B. R., Thallapally, P. K. \& Nangia, A. (2004). Cryst. Growth Des. 4, 215-218.

Byrn, S. R., Stowell, J. G. \& Pfeiffer, R. R. (1999). In Solid State Chemistry of Drugs, 2nd ed. West Lafayette, IN, USA: SSCI Press. Chen, L.-Z. (2009). Acta Cryst. E65, o2626.

Desiraju, G. R., Vittal, J. J. \& Ramanan, A. (2011). In Crystal Engineering A Textbook. Singapore: World Scientific Publishing.

Dubey, R. \& Desiraju, G. R. (2014). Chem. Commun. 50, 1181-1184. Gholivand, K., Zare, K., Afshar, F., Shariatinia, Z. \& Khavasi, H. R. (2007). Acta Cryst. E63, o4027.

Groom, C. R. \& Allen, F. H. (2014). Angew. Chem. Int. Ed. 53, 662671.

Gubin, A. I., Nurakhmetov, N. N., Buranbaev, M. Zh., Mul'kina, R. I. \& Erkasov, R. Sh. (1989). Kristallografiya(Russ.)(Crystallogr. Rep.), 34, 238-239.

Kerr, H. E., Softley, L. K., Suresh, K., Nangia, A., Hodgkinson, P. \& Evans, I. R. (2015). CrystEngComm, 17, 6707-6715.

Li, J., Bourne, S. A. \& Caira, M. R. (2011). Chem. Commun. 47, 15301532.

Macrae, C. F., Bruno, I. J., Chisholm, J. A., Edgington, P. R., McCabe, P., Pidcock, E., Rodriguez-Monge, L., Taylor, R., van de Streek, J. \& Wood, P. A. (2008). J. Appl. Cryst. 41, 466-470.

Nattinen, K. I. \& Rissanen, K. (2003). CrystEngComm, 5, 326-330.

Sheldrick, G. M. (2008). Acta Cryst. A64, 112-122.

Sheldrick, G. M. (2015a). Acta Cryst. A71, 3-8.
Table 2

Experimental details.

\begin{tabular}{|c|c|}
\hline \multicolumn{2}{|l|}{ Crystal data } \\
\hline Chemical formula & $\mathrm{C}_{6} \mathrm{H}_{7} \mathrm{~N}_{2} \mathrm{O}^{+} \cdot \mathrm{Cl}^{-}$ \\
\hline$M_{\mathrm{r}}$ & 158.59 \\
\hline Crystal system, space group & Monoclinic, $C 2 / c$ \\
\hline Temperature (K) & 150 \\
\hline$a, b, c(\AA)$ & $24.960(2), 5.1055(4), 12.4664(9)$ \\
\hline$\beta\left(^{\circ}\right)$ & $117.545(5)$ \\
\hline$V\left(\AA^{3}\right)$ & $1408.6(2)$ \\
\hline$Z$ & 8 \\
\hline Radiation type & Mo $K \alpha$ \\
\hline$\mu\left(\mathrm{mm}^{-1}\right)$ & 0.47 \\
\hline Crystal size $(\mathrm{mm})$ & $0.34 \times 0.28 \times 0.26$ \\
\hline \multicolumn{2}{|l|}{ Data collection } \\
\hline Diffractometer & Stoe IPDS 2 \\
\hline Absorption correction & $\begin{array}{l}\text { Analytical }(X-R E D \text { and } X- \\
\quad \text { SHAPE; Stoe \& Cie, 2012) }\end{array}$ \\
\hline$T_{\min }, T_{\max }$ & $0.861,0.913$ \\
\hline $\begin{array}{l}\text { No. of measured, independent and } \\
\text { observed }[I>2 \sigma(I)] \text { reflections }\end{array}$ & $4768,1865,1520$ \\
\hline$R_{\text {int }}$ & 0.047 \\
\hline$(\sin \theta / \lambda)_{\max }\left(\AA^{-1}\right)$ & 0.685 \\
\hline \multicolumn{2}{|l|}{ Refinement } \\
\hline$R\left[F^{2}>2 \sigma\left(F^{2}\right)\right], w R\left(F^{2}\right), S$ & $0.034,0.093,1.01$ \\
\hline No. of reflections & 1865 \\
\hline No. of parameters & 104 \\
\hline No. of restraints & 8 \\
\hline $\mathrm{H}$-atom treatment & $\begin{array}{l}\mathrm{H} \text { atoms treated by a mixture of } \\
\text { independent and constrained } \\
\text { refinement }\end{array}$ \\
\hline$\Delta \rho_{\max }, \Delta \rho_{\min }\left(\mathrm{e} \AA^{-3}\right)$ & $0.45,-0.48$ \\
\hline
\end{tabular}

Computer programs: $X$-AREA (Stoe \& Cie, 2012), X-RED (Stoe \& Cie, 2012), SHELXT (Sheldrick, 2015a), SHELXL2014 (Sheldrick, 2015b), SHELXTL (Sheldrick, 2008) and Mercury (Macrae et al., 2008).

Sheldrick, G. M. (2015b). Acta Cryst. C71, 3-8.

Slouf, M. (2001). Acta Cryst. E57, o61-o62.

Stoe \& Cie (2012). $X$-SHAPE and $X$-RED. Stoe \& Cie, Darmstadt, Germany.

Thompson, L. J., Voguri, R. S., Male, L. \& Tremayne, M. (2011). CrystEngComm, 13, 4188-4195.

Tothadi, S. \& Desiraju, G. R. (2012). Phil. Trans. R. Soc. A, 370, 2900 2915.

Vishweshwar, P., Nangia, A. \& Lynch, V. M. (2003). CrystEngComm, 5, 164-168.

Zhao, G.-Q., Pan, Z.-F. \& Tang, X.-X. (2008). Acta Cryst. E64, o138. 


\section{supporting information}

Acta Cryst. (2016). E72, 436-439 [https://doi.org/10.1107/S2056989016003340]

\section{Crystal structure of 4-carbamoylpyridinium chloride}

\section{Simon M. Fellows and Timothy J. Prior}

Computing details

Data collection: $X$-AREA (Stoe \& Cie, 2012); cell refinement: $X$-AREA (Stoe \& Cie, 2012); data reduction: $X$-RED (Stoe $\&$ Cie, 2012); program(s) used to solve structure: SHELXT (Sheldrick, 2015a); program(s) used to refine structure: SHELXL2014 (Sheldrick, 2015b); molecular graphics: SHELXTL (Sheldrick, 2008) and Mercury (Macrae et al., 2008); software used to prepare material for publication: SHELXL2014 (Sheldrick, 2015b).

4-Carbamoylpyridinium chloride

Crystal data

$\mathrm{C}_{6} \mathrm{H}_{7} \mathrm{~N}_{2} \mathrm{O}^{+} \cdot \mathrm{Cl}^{-}$

$M_{r}=158.59$

Monoclinic, $C 2 / c$

$a=24.960(2) \AA$

$b=5.1055(4) \AA$

$c=12.4664(9) \AA$

$\beta=117.545(5)^{\circ}$

$V=1408.6(2) \AA^{3}$

$Z=8$

Data collection

Stoe IPDS 2 diffractometer

Radiation source: fine-focus sealed X-ray tube Detector resolution: 6.67 pixels $\mathrm{mm}^{-1}$

$\omega$ scans

Absorption correction: analytical (X-RED and X-SHAPE; Stoe \& Cie, 2012)

$T_{\text {min }}=0.861, T_{\max }=0.913$

Refinement

Refinement on $F^{2}$

Least-squares matrix: full

$R\left[F^{2}>2 \sigma\left(F^{2}\right)\right]=0.034$

$w R\left(F^{2}\right)=0.093$

$S=1.01$

1865 reflections

104 parameters

8 restraints
$F(000)=656$

$D_{\mathrm{x}}=1.496 \mathrm{Mg} \mathrm{m}^{-3}$

Mo $K \alpha$ radiation, $\lambda=0.71073 \AA$

Cell parameters from 5016 reflections

$\theta=3.7-59.1^{\circ}$

$\mu=0.47 \mathrm{~mm}^{-1}$

$T=150 \mathrm{~K}$

Block, colourless

$0.34 \times 0.28 \times 0.26 \mathrm{~mm}$

4768 measured reflections

1865 independent reflections

1520 reflections with $I>2 \sigma(I)$

$R_{\text {int }}=0.047$

$\theta_{\max }=29.2^{\circ}, \theta_{\min }=1.8^{\circ}$

$h=-34 \rightarrow 34$

$k=-6 \rightarrow 6$

$l=-17 \rightarrow 17$

Hydrogen site location: mixed

$\mathrm{H}$ atoms treated by a mixture of independent and constrained refinement

$w=1 /\left[\sigma^{2}\left(F_{0}^{2}\right)+(0.0636 P)^{2}\right]$

where $P=\left(F_{\mathrm{o}}^{2}+2 F_{\mathrm{c}}^{2}\right) / 3$

$(\Delta / \sigma)_{\max }=0.001$

$\Delta \rho_{\max }=0.45$ e $\AA^{-3}$

$\Delta \rho_{\min }=-0.48$ e $\AA^{-3}$ 


\section{Special details}

Geometry. All esds (except the esd in the dihedral angle between two 1.s. planes) are estimated using the full covariance matrix. The cell esds are taken into account individually in the estimation of esds in distances, angles and torsion angles; correlations between esds in cell parameters are only used when they are defined by crystal symmetry. An approximate (isotropic) treatment of cell esds is used for estimating esds involving l.s. planes.

Refinement. Refinement of $F^{2}$ against ALL reflections. The weighted $R$-factor $w R$ and goodness of fit $S$ are based on $F^{2}$, conventional $R$-factors $R$ are based on $F$, with $F$ set to zero for negative $F^{2}$. The threshold expression of $F^{2}>\sigma\left(F^{2}\right)$ is used only for calculating $R$-factors (gt) etc. and is not relevant to the choice of reflections for refinement. $R$-factors based on $F^{2}$ are statistically about twice as large as those based on $F$, and $R$ - factors based on ALL data will be even larger.

Fractional atomic coordinates and isotropic or equivalent isotropic displacement parameters $\left(\hat{A}^{2}\right)$

\begin{tabular}{lllll}
\hline & $x$ & $y$ & $z$ & $U_{\text {iso }} / U_{\text {eq }}$ \\
\hline C11 & $0.05337(2)$ & $1.08640(7)$ & $0.66004(3)$ & $0.02094(12)$ \\
C1 & $0.14210(7)$ & $0.6050(3)$ & $0.62858(14)$ & $0.0235(3)$ \\
H1 & $0.1565(2)$ & $0.7082(17)$ & $0.7004(12)$ & $0.028^{*}$ \\
C2 & $0.17821(6)$ & $0.4124(3)$ & $0.61830(13)$ & $0.0206(3)$ \\
H2 & $0.2164(7)$ & $0.3837(6)$ & $0.6800(11)$ & $0.025^{*}$ \\
C3 & $0.15607(5)$ & $0.2616(3)$ & $0.51318(11)$ & $0.0175(3)$ \\
C4 & $0.09760(6)$ & $0.3065(3)$ & $0.42116(13)$ & $0.0236(3)$ \\
H4 & $0.0814(3)$ & $0.2027(17)$ & $0.3497(12)$ & $0.028^{*}$ \\
C5 & $0.06356(7)$ & $0.5048(3)$ & $0.43560(14)$ & $0.0270(3)$ \\
H5 & $0.0247(7)$ & $0.5390(7)$ & $0.3747(12)$ & $0.032^{*}$ \\
C6 & $0.19697(6)$ & $0.0497(3)$ & $0.50687(12)$ & $0.0173(3)$ \\
N1 & $0.08665(6)$ & $0.6468(2)$ & $0.53714(12)$ & $0.0228(3)$ \\
H1A & $0.0642(4)$ & $0.775(2)$ & $0.54449(16)$ & $0.027^{*}$ \\
N2 & $0.17626(5)$ & $-0.0961(2)$ & $0.40762(11)$ & $0.0209(3)$ \\
O1 & $0.24768(4)$ & $0.0199(2)$ & $0.59516(9)$ & $0.0228(2)$ \\
H2A & $0.2004(8)$ & $-0.216(4)$ & $0.4039(16)$ & $0.027^{*}$ \\
H2B & $0.1426(8)$ & $-0.069(4)$ & $0.3420(17)$ & $0.027^{*}$ \\
& & & & \\
\hline
\end{tabular}

Atomic displacement parameters $\left(\AA^{2}\right)$

\begin{tabular}{lllllll}
\hline & $U^{11}$ & $U^{22}$ & $U^{33}$ & $U^{12}$ & $U^{13}$ & $U^{23}$ \\
\hline C11 & $0.01780(17)$ & $0.0231(2)$ & $0.01907(18)$ & $0.00607(12)$ & $0.00610(13)$ & $-0.00009(13)$ \\
C1 & $0.0261(7)$ & $0.0220(7)$ & $0.0249(7)$ & $-0.0003(5)$ & $0.0138(6)$ & $-0.0034(6)$ \\
C2 & $0.0179(6)$ & $0.0215(7)$ & $0.0208(6)$ & $0.0012(5)$ & $0.0075(5)$ & $-0.0015(5)$ \\
C3 & $0.0171(6)$ & $0.0167(6)$ & $0.0190(6)$ & $0.0021(5)$ & $0.0087(5)$ & $0.0014(5)$ \\
C4 & $0.0195(6)$ & $0.0255(8)$ & $0.0212(6)$ & $0.0065(5)$ & $0.0056(5)$ & $-0.0034(6)$ \\
C5 & $0.0207(7)$ & $0.0294(8)$ & $0.0277(7)$ & $0.0091(6)$ & $0.0086(6)$ & $0.0003(6)$ \\
C6 & $0.0155(6)$ & $0.0170(7)$ & $0.0190(6)$ & $0.0022(5)$ & $0.0075(5)$ & $0.0013(5)$ \\
N1 & $0.0236(6)$ & $0.0195(6)$ & $0.0303(7)$ & $0.0055(5)$ & $0.0166(5)$ & $0.0003(5)$ \\
N2 & $0.0173(5)$ & $0.0217(6)$ & $0.0198(6)$ & $0.0061(4)$ & $0.0052(5)$ & $-0.0024(5)$ \\
O1 & $0.0170(4)$ & $0.0250(6)$ & $0.0202(5)$ & $0.0067(4)$ & $0.0034(4)$ & $-0.0015(4)$ \\
\hline
\end{tabular}

Geometric parameters $\left(\AA,{ }^{\circ}\right)$

\begin{tabular}{llll}
\hline $\mathrm{C} 1-\mathrm{N} 1$ & $1.342(2)$ & $\mathrm{C} 4-\mathrm{H} 4$ & $0.951(16)$ \\
$\mathrm{C} 1-\mathrm{C} 2$ & $1.3795(19)$ & $\mathrm{C} 5-\mathrm{N} 1$ & $1.336(2)$
\end{tabular}




$\begin{array}{llll}\mathrm{C} 1-\mathrm{H} 1 & 0.955(16) & \mathrm{C} 5-\mathrm{H} 5 & 0.931(18) \\ \mathrm{C} 2-\mathrm{C} 3 & 1.3948(19) & \mathrm{C} 6-\mathrm{O} 1 & 1.2443(17) \\ \mathrm{C} 2-\mathrm{H} 2 & 0.918(16) & \mathrm{C} 6-\mathrm{N} 2 & 1.3271(18) \\ \mathrm{C} 3-\mathrm{C} 4 & 1.3964(18) & \mathrm{N} 1-\mathrm{H} 1 \mathrm{~A} & 0.894(14) \\ \mathrm{C} 3-\mathrm{C} 6 & 1.5141(18) & \mathrm{N} 2-\mathrm{H} 2 \mathrm{~A} & 0.876(16) \\ \mathrm{C} 4-\mathrm{C} 5 & 1.3858(19) & \mathrm{N} 2-\mathrm{H} 2 \mathrm{~B} & 0.871(18) \\ & & & 119.84(14) \\ \mathrm{N} 1-\mathrm{C} 1-\mathrm{C} 2 & 119.73(14) & \mathrm{N} 1-\mathrm{C} 5-\mathrm{C} 4 & 120.1 \\ \mathrm{~N} 1-\mathrm{C} 1-\mathrm{H} 1 & 120.1 & \mathrm{~N} 1-\mathrm{C} 5-\mathrm{H} 5 & 120.1 \\ \mathrm{C} 2-\mathrm{C} 1-\mathrm{H} 1 & 120.1 & \mathrm{C} 4-\mathrm{C} 5-\mathrm{H} 5 & 123.66(12) \\ \mathrm{C} 1-\mathrm{C} 2-\mathrm{C} 3 & 119.26(13) & \mathrm{O} 1-\mathrm{C} 6-\mathrm{C} 3 & 118.43(12) \\ \mathrm{C} 1-\mathrm{C} 2-\mathrm{H} 2 & 120.4 & \mathrm{~N} 2-\mathrm{C} 6-\mathrm{C} 3 & 117.91(12) \\ \mathrm{C} 3-\mathrm{C} 2-\mathrm{H} 2 & 120.4 & \mathrm{C} 5-\mathrm{N} 1-\mathrm{C} 1 & 118.6 \\ \mathrm{C} 2-\mathrm{C} 3-\mathrm{C} 4 & 119.39(12) & \mathrm{C} 5-\mathrm{N} 1-\mathrm{H} 1 \mathrm{~A} & 118.6 \\ \mathrm{C} 2-\mathrm{C} 3-\mathrm{C} 6 & 117.34(11) & \mathrm{C} 6-\mathrm{N} 1-\mathrm{H} 1 \mathrm{~A}-\mathrm{H} 2 \mathrm{~A} & 117.5(12) \\ \mathrm{C} 4-\mathrm{C} 3-\mathrm{C} 6 & 123.25(12) & \mathrm{C} 6-\mathrm{N} 2-\mathrm{H} 2 \mathrm{~B} & 125.3(12) \\ \mathrm{C} 5-\mathrm{C} 4-\mathrm{C} 3 & 118.94(14) & \mathrm{H} 2 \mathrm{~A}-\mathrm{N} 2-\mathrm{H} 2 \mathrm{~B} & 116.7(16) \\ \mathrm{C} 5-\mathrm{C} 4-\mathrm{H} 4 & 120.5 & & \end{array}$

Hydrogen-bond geometry $\left(\AA,{ }^{\circ}\right)$

\begin{tabular}{lllll}
\hline$D-\mathrm{H} \cdots A$ & $D-\mathrm{H}$ & $\mathrm{H} \cdots A$ & $D \cdots A$ & $D-\mathrm{H} \cdots A$ \\
\hline $\mathrm{C} 1-\mathrm{H} 1 \cdots \mathrm{O} 1^{\mathrm{i}}$ & 0.95 & 2.74 & $3.295(2)$ & 118 \\
$\mathrm{C} 2-\mathrm{H} 2 \cdots \mathrm{O} 1^{\mathrm{i}}$ & 0.92 & 2.61 & $3.2205(18)$ & 124 \\
$\mathrm{C} 4-\mathrm{H} 4 \cdots \mathrm{C} 11^{\mathrm{ii}}$ & 0.95 & 2.59 & $3.5377(15)$ & 172 \\
$\mathrm{C} 5-\mathrm{H} 5 \cdots \mathrm{Cl} 1^{\mathrm{iii}}$ & 0.93 & 2.62 & $3.3284(15)$ & 133 \\
$\mathrm{~N} 1-\mathrm{H} 1 A \cdots \mathrm{C} 11$ & 0.89 & 2.24 & $3.0416(12)$ & 149 \\
$\mathrm{~N} 1-\mathrm{H} 1 A \cdots \mathrm{C} 11^{\mathrm{iii}}$ & 0.89 & 2.95 & $3.4882(13)$ & 121 \\
$\mathrm{~N} 2-\mathrm{H} 2 A \cdots \mathrm{O} 1^{\text {iv }}$ & $0.88(2)$ & $2.02(2)$ & $2.8892(15)$ & $174(2)$ \\
$\mathrm{N} 2-\mathrm{H} 2 B \cdots \mathrm{C} 11^{\mathrm{ii}}$ & $0.87(2)$ & $2.33(2)$ & $3.1907(13)$ & $169(2)$ \\
\hline
\end{tabular}

Symmetry codes: (i) $-x+1 / 2, y+1 / 2,-z+3 / 2$; (ii) $x,-y+1, z-1 / 2$; (iii) $-x,-y+2,-z+1$; (iv) $-x+1 / 2,-y-1 / 2,-z+1$. 